\title{
HETEROSIS DE CRUZAS ENTRE LINEAS DE TOMATE (Solanum lycopersicum L.) NATIVO MEXICANO TIPO PIMIENTO Y LINEAS TIPO SALADETTE
}

\section{HETEROSIS IN CROSSES AMONG BELL PEPPER-SHAPED MEXICAN NATIVE TOMATO (Solanum lycopersicum L.) LINES AND SALADETTE TYPE LINES}

\author{
Esaú de-los-Ángeles Martínez-Vázquez¹, Ricardo Lobato-Ortiz*, \\ J. Jesús García-Zavala' y Delfino Reyes-López ${ }^{2}$
}

\begin{abstract}
'Postgrado en Recursos Genéticos y Productividad-Genética, Campus Montecillo, Colegio de Postgraduados. Km 36.5 Carr. México-Texcoco. 56230, Montecillo, Texcoco, Edo. de México. ${ }^{2}$ Facultad de Ingeniería Agrohidráulica, Benemérita Universidad Autónoma de Puebla. San Juan Acateno, Teziutlán, Puebla.

*Autor para correspondencia (rlobato@colpos.mx)
\end{abstract}

\section{RESUMEN}

En México el tomate o jitomate (Solanum lycopersicum L.) es una de las hortalizas de mayor importancia por su superficie cultivada, por las divisas y el número de empleos que genera, y por su valor alimenticio y cultural. Sin embargo, el material nativo mexicano "criollo" se ha estudiado poco en cuanto a su rendimiento, calidad, resistencia a factores bióticos y abióticos, y en su potencial como fuente de germoplasma en programas de mejoramiento genético. En este trabajo se evaluó el comportamiento heterótico de 40 cruzas formadas entre 10 líneas S5 derivadas de colectas de jitomate nativo mexicano tipo pimiento, localmente llamado "chino criollo", y cuatro líneas S5 derivadas de híbridos comerciales de jitomate tipo "saladette". El experimento se estableció en condiciones de invernadero e hidroponía, en un diseño experimental de bloques completos al azar con tres repeticiones y cinco plantas por repetición. Las variables que se registraron fueron peso total de fruto (PTF), peso promedio de fruto (PPF), número total de frutos (NTF), firmeza del fruto (FF), número de flores del tercer racimo (NFR3), número de racimos por planta (NRP) y días a floración del primer racimo (DF1). Hubo diferencias significativas $(P \leq 0.01)$ entre genotipos, cruzas, líneas y grupos de materiales para la mayoría de las variables. La cruza de mayor rendimiento fue LOR111R, con $3624 \mathrm{~g} /$ planta, seguida del testigo El Cid con $34529 \mathrm{~g} /$ planta. En las variables PMF, NTF y NRP las cruzas al menos igualaron y en algunos casos superaron al híbrido testigo. Se obtuvieron valores positivos de heterosis media para la mayoría de las variables, excepto en días a floración. En el rendimiento de fruto la heterosis media varió de -21.8 a $111.2 \%$, mientras que para PPF fue de -13 a $80.7 \%$. Los resultados del comportamiento per se de las líneas y de sus cruzamientos indican una amplia divergencia genética, la cual se reflejó en altos rendimiento y alta heterosis media que se pueden aprovechar en programas de mejoramiento genético de jitomate.

Palabras claves: Solanum lycopersicum, tomate nativo mexicano, heterosis.

\section{SUMMARY}

Tomato (Solanum lycopersicum L.) is one of the most important vegetables cultivated in México due to its cultivated surface, its commodity status, the number of jobs required for production, and its nutritional and cultural value. However, little is known about the native Mexican landraces in terms of yield performance, fruit quality, resistance to biotic and abiotic factors, and their potential as a source of germplasm for plant breeding programs. In this work, heterotic performance of 40 crosses formed among $10 \mathrm{~S} 5$ lines derived from Mexican native tomato pepper type accessions, locally called "Chino Criollo", and four S5 lines originated from commercial hybrids of "saladette" type was evaluated. The experiment was carried out under greenhouse and hydroponics conditions, in a randomized complete block design with three replications and five plants per replication. Traits evaluated were total weight of fruit (PTF), average fruit weight (PPF), total number of fruits (NTF), fruit firmness (FF), number of flowers in the third cluster (NFR3), number of clusters per plant (NRP), and days to flowering in the first cluster (DF1). There were significant differences $(P \leq 0.01)$ between genotypes, crosses, lines and groups of genetic materials for most variables. The cross with the highest yield was LOR $111 \mathrm{R}$ with $3624 \mathrm{~g} \mathrm{plant}^{-1}$, followed by the control variety El Cid, with $3452 \mathrm{~g} \mathrm{plant}^{-1}$ For traits PPF, NTF and NRP, there were some crosses that at least equaled and in some cases exceeded the values of the hybrid control variety. Positive values for mean heterosis were obtained in most variables, except for days to flowering. For fruit yield the mean heterosis ranged from -21.8. to 111.2 $\%$, whereas for PPF it was -13 to $80.7 \%$. Results for the per se performance of the lines and their crosses show great genetic divergence among native genetic materials, which was reflected in high yields and high mean heterosis that can be exploited in tomato breeding programs.

Index words: Solanum lycopersicum, Mexican native tomatoes, heterosis.

\section{INTRODUCCIÓN}

En México el tomate o jitomate cultivado (Solanum lycopersicum L.) ocupa el segundo lugar en importancia entre las hortalizas, con 2.7 millones de toneladas producidas anualmente (SIAP, 2013). En las últimas décadas los híbridos de jitomate han destacado por su mayor rendimiento, resistencia a enfermedades, calidad de fruto y vida de anaquel (Grandillo et al., 1999). Sin embargo, las variedades comerciales que se cultivan en este país, en condiciones de invernadero y a cielo abierto, son híbridos con reducida base genética producidos por empresas transnacionales (Hernández-Leal et al., 2013).

Los jitomates silvestres, o con algún grado de domesticación, que se cultivan como "materiales criollos" se encuentran en todo el país (Chávez-Servia et al., 2011; Lobato-Ortiz et al., 2012; Sánchez-Peña et al., 2006), tanto en zonas de vegetación natural como en campos de 
cultivo, donde eventualmente pueden convertirse en malezas (Bonilla-Barrientos et al., 2014; Sánchez-Peña et al., 2006). La amplia distribución de este tipo de jitomate ha permitido desarrollar poblaciones con diversos grados de adaptación a factores abióticos extremos y con resistencia a plagas y enfermedades, lo que ha incrementado la variabilidad biológica de la especie (Ramanatha y Hodking, 2002). En consecuencia, se requiere estudiar el material nativo mexicano per se y en combinaciones híbridas, para generar germoplasma útil a los programas nacionales de mejoramiento genético, con mejor adaptación y que permita la eventual obtención de líneas, variedades sintéticas e híbridos.

Existen estudios relacionados con la caracterización per se de poblaciones nativas de jitomate mexicano (BonillaBarrientos et al., 2014; Carrillo-Rodríguez y Chávez-Servia, 2010; Crisanto-Juárez et al., 2010; Estrada-Trejo et al., 2014), aunque pocos se han enfocado al estudio de combinaciones híbridas y al subsecuente análisis de la heterosis (Hernández-Bautista et al., 2014) de variables relacionadas con la calidad, rendimiento y características agromorfológicas de ese germoplasma (Crisanto-Juárez et al., 2010).

Con base en lo anterior, los objetivos del presente trabajo fueron evaluar el comportamiento agronómico de híbridos de jitomate obtenidos de cruzamientos entre líneas derivadas de jitomate nativo mexicano tipo pimiento y líneas derivadas de híbridos comerciales tipo "saladette", para identificar germoplasma con alto potencial de rendimiento y buena heterosis.

\section{MATERIALES Y MÉTODOS}

\section{Material vegetal}

Se generaron 40 híbridos mediante el cruzamiento de diez líneas S5 de jitomate nativo denominado localmente "chino criollo, tipo pimiento o cuadrado", el cual es de importancia económica regional en los estados de Puebla y Oaxaca (Bonilla-Barrientos et al., 2014), con cuatro líneas avanzadas también S5 de tipo "saladette" $(L, C, R, T)$ derivadas de híbridos comerciales. Las 10 primeras líneas provenían de diferentes colectas de la región de Tehuacán, Puebla y Oaxaca. En la partición de los genotipos en grupos de materiales del análisis de varianza, las cuatro líneas tipo "saladette" se consideraron como probadores y cada una de ellas se cruzó con las 10 primeras líneas. En la evaluación se incluyeron esas 10 líneas (hembras), las cuatro líneas avanzadas (machos), y un híbrido comercial tipo "saladette" como testigo (El Cid). Las líneas nativas se identificaron como LOR-79, LOR-81, LOR-82, LOR-84, LOR-85, LOR-91, LOR-95, LOR-97, LOR-103 y LOR-111(Figura 1), mientras que las cruzas se denominaron con el nombre de la línea seguida por la inicial L, C, R o T, según el probador empleado.

\section{Diseño experimental y manejo agronómico}

Los 55 genotipos resultantes se evaluaron en condiciones de invernadero e hidroponía en el ciclo Primavera-Verano 2014, en Montecillo, Texcoco, Estado de México (19 $30^{\prime} \mathrm{N}, 98^{\circ} 53^{\prime} \mathrm{O}$ y $2250 \mathrm{~m}$ de altitud). Se usó un diseño de bloques completos al azar con tres repeticiones y 5 plantas por repetición. La siembra se realizó el 19 de diciembre de 2013 y el trasplante el 30 de enero de 2014. El trasplante se hizo en bolsas de polietileno de color negro de $12 \mathrm{~L}$ (40 $x 40 \mathrm{~cm}$ ), rellenadas con tezontle rojo fino como sustrato, con una distancia entre filas de bolsas de $1 \mathrm{~m}$ y entre plantas de $0.4 \mathrm{~m}$ (25,000 plantas ha-1). Las plantas se manejaron a un solo tallo y se sujetaron con hilo de rafia. Se aplicaron cuatro riegos al día con la solución nutritiva de Steiner (1984); el pH de la solución se ajustó entre 5.5 a 6.0. La cosecha fue manual, planta por planta, en dos cortes a los 120 y 144 d después del trasplante.

\section{Variables registradas}

En cada planta se tomaron datos del rendimiento de fruto (peso total de frutos por planta en g, PTF) y número total de frutos (NTF) con base en la suma de los dos cortes; número de flores del tercer racimo (NFR3); número de racimos (NRP) a los 90 d, y días a floración del primer racimo (DF1) cuando las plantas presentaron la antesis de la primera flor. Además, en una muestra representativa de cinco frutos por planta, típicos del fenotipo y bien polinizados (usualmente del tercer racimo), se registró el peso promedio de fruto (g, PPF) y la firmeza del fruto (en newtons $-\mathrm{N}-, \mathrm{FF}$ ), medida con un texturómetro universal marca FORCEFIVE ${ }^{\circledR}$ modelo FDV-30 (USA) con puntal cónico de 0.8 $\mathrm{mm}$. Estas dos últimas variables se midieron únicamente en frutos del primer corte.

\section{Análisis estadístico}

Los datos se analizaron mediante análisis de varianza y correlaciones; la comparación de medias fue mediante Tukey $(P \leq 0.05)$; para estos análisis se empleó el paquete estadístico SAS versión 9.0 (SAS Institute, 2002). El análisis de varianza se realizó con los 55 genotipos, los cuales se partieron en 40 cruzas, 10 líneas S5 nativas, cuatro líneas "saladette" S5 (probadores), y cuatro grupos de materiales genéticos conformados por las cruzas, las líneas nativas, los probadores, y el testigo El Cid.

El cálculo de la heterosis media porcentual $(\mathrm{Hm})$ se estimó con respecto al promedio de los progenitores mediante la fórmula: 


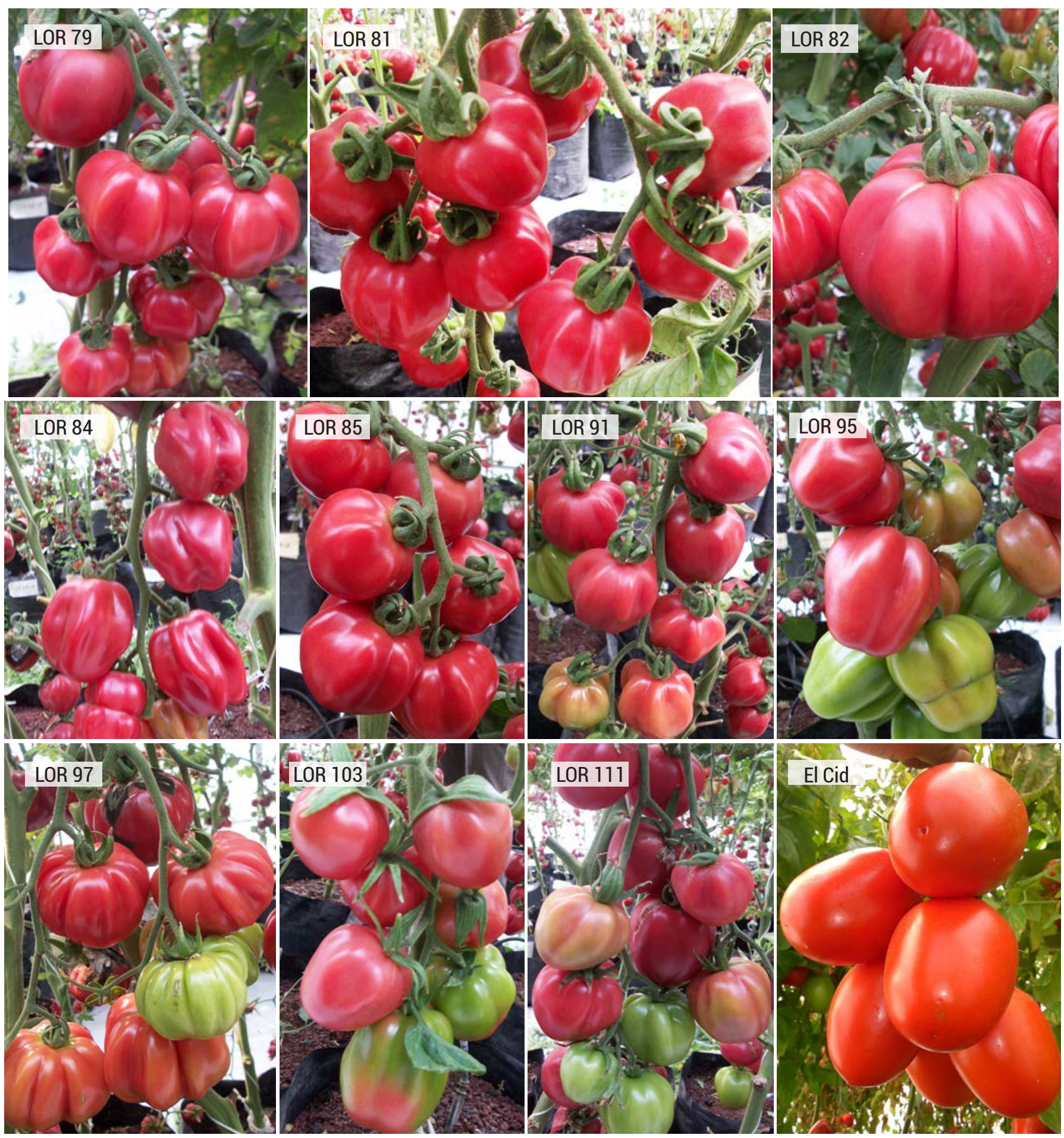

Figura 1. Frutos de 10 líneas (LOR) de tomate (Solanum lycopersicum L.) derivadas de poblaciones nativas empleadas en este estudio, en comparación con frutos del híbrido comercial El Cid. 


$$
H m=\frac{F 1-P M}{P M} \times 100
$$

donde: $F_{7}=$ media fenotípica de la población $F_{1} ; P M=\left(P_{i}+\right.$ $\left.P_{j}\right) / 2$ = media fenotípica del promedio de los progenitores iy $j$.

Para el cálculo de la heterosis superior $(H s)$ se usó la misma fórmula, pero el valor de PM se sustituyó por el valor del mejor progenitor.

\section{RESULTADOS Y DISCUSIÓN}

\section{Análisis de varianza}

Se detectaron diferencias significativas $(P \leq 0.01)$ entre genotipos en todas las variables medidas (Cuadro 1). La partición en cruzas, líneas y grupos de genotipos detectó significancia entre cruzas y entre líneas para todas las variables; entre probadores no hubo diferencias para rendimiento, firmeza de fruto, número de racimos por planta y días a floración del primer racimo, mientras que entre los grupos de materiales genéticos (cruzas, líneas, probadores y el testigo) hubo significancia para todas las variables, excepto para firmeza del fruto y número de flores del tercer racimo.

Estos resultados demuestran que entre los genotipos existe amplia variabilidad para rendimiento y sus componentes. Esta variabilidad genética se atribuye a la selección tradicional de plantas y frutos para semilla que el productor hace ciclo tras ciclo en sus parcelas, lo cual imprime características genéticas específicas a cada material criollo del cual se derivaron las líneas que se emplearon como progenitores femeninos de las cruzas, así como a los di- ferentes orígenes geográficos de los mismos (PachecoTriste et al., 2014; Ramanatha y Hodgkin, 2002). La ausencia de significancia entre los probadores para rendimiento se debió probablemente a su menor variación genética, pues éstos provinieron de materiales comerciales "saladette" cuya base genética es reducida (Álvarez et al., 2009; Grandillo et al., 1999; Miller y Tanskley, 1990). Con base en estos resultados es posible seleccionar las mejores líneas nativas, las mejores líneas "saladette" (probadores), y las mejores cruzas para iniciar un programa de mejoramiento genético.

\section{Comparación de medias}

La cruza LOR111R fue la de mayor rendimiento de fruto, con $3624 \mathrm{~g} /$ planta, estadísticamente igual al híbrido testigo 'El Cid' (3452 g/planta) y a ocho cruzas más (Cuadro 2), lo que muestra el alto potencial de rendimiento de las líneas en combinaciones híbridas, especialmente con el probador R. Por otro lado, los cinco materiales genéticos de menor rendimiento (entre 911 y $1096 \mathrm{~g} /$ planta) correspondieron a líneas nativas per se. Estas diferencias en rendimiento entre líneas y cruzas pueden atribuirse a que en estas últimas se explotan tanto efectos aditivos como de dominancia, mientras que en las líneas solo operan los efectos aditivos (Escorcia et al., 2010; Reyes et al., 2004). Por otra parte, la endogamia de las líneas no debería ser un factor que contribuya significativamente a su más bajo rendimiento, ya que la depresión endogámica en especies autógamas es relativamente pequeña en comparación con la que se esperaría en especies alógamas (Charlesworth y Charlesworth, 1987).

Para peso promedio de fruto (Cuadro 2), cinco cruzas experimentales y una línea (LOR82) igualaron al testigo

Cuadro 1. Cuadrados medios de siete variables evaluadas en 55 genotipos de jitomate nativo tipo pimiento, tipo "saladette" y un testigo comercial.

\begin{tabular}{lrrrrrrrr}
\hline FV & \multicolumn{1}{c}{ REP } & GENOTIPOS & CRUZAS & LÍNEAS & PROB & GRUPOS & ERROR & CV (\%) \\
\hline PTF & $113,064.8 \mathrm{~ns}$ & $1,455,913.6 * *$ & $1,044,473.7 * *$ & $312,850.4 * *$ & $789,464.8 \mathrm{~ns}$ & $10,900,271.0 * *$ & $97,334.6$ & 15 \\
PPF & $46.0 \mathrm{~ns}$ & $2263.4 * *$ & $1338.8 * *$ & $5269.8 * *$ & $564.2 *$ & $6962.8 * *$ & 34.0 & 4 \\
NTF & $29.8 *$ & $776.2 * *$ & $739.0 * *$ & $248.3 * *$ & $1938.6 * *$ & $1681.6 * *$ & 7.7 & 6 \\
FF & $4.9 * *$ & $1.6 * *$ & $1.8 * *$ & $1.4 * *$ & $0.5 \mathrm{~ns}$ & $0.7 \mathrm{~ns}$ & 0.2 & 13 \\
NFR3 & $1.2 \mathrm{~ns}$ & $7.9 * *$ & $7.8 * *$ & $7.2 * *$ & $12.2 * *$ & $8.0 \mathrm{~ns}$ & 0.9 & 11 \\
NRP & $0.2 \mathrm{~ns}$ & $2.2 * *$ & $1.3 * *$ & $0.9 * *$ & $0.5 \mathrm{~ns}$ & $19.5 * *$ & 0.2 & 5 \\
DF1 & $5.3 \mathrm{~ns}$ & $107.5 * *$ & $36.1 * *$ & $92.1 * *$ & $9.5 \mathrm{~ns}$ & $1180.2 * *$ & 5.3 & 8 \\
GL & 2 & 54 & 39 & 9 & 3 & 3 & 108 & \\
\hline
\end{tabular}

$* *, *=$ significativo a $\mathrm{P} \leq 0.01$ y $\mathrm{P} \leq 0.05$, respectivamente, $\mathrm{ns}=$ no significativo, $\mathrm{REP}=$ repeticiones, $\mathrm{PROB}=$ probadores, $\mathrm{CV}=$ coeficiente de variación $\mathrm{PTF}=$ peso total de frutos, $\mathrm{PPF}=$ peso promedio de frutos, NTF = número total de frutos, FF = firmeza del fruto, NFR3 = número de flores del tercer racimo, $\mathrm{NRP}=$ número de racimos por planta, DF1 = días a floración del primer racimo, GL = grados de libertad. 


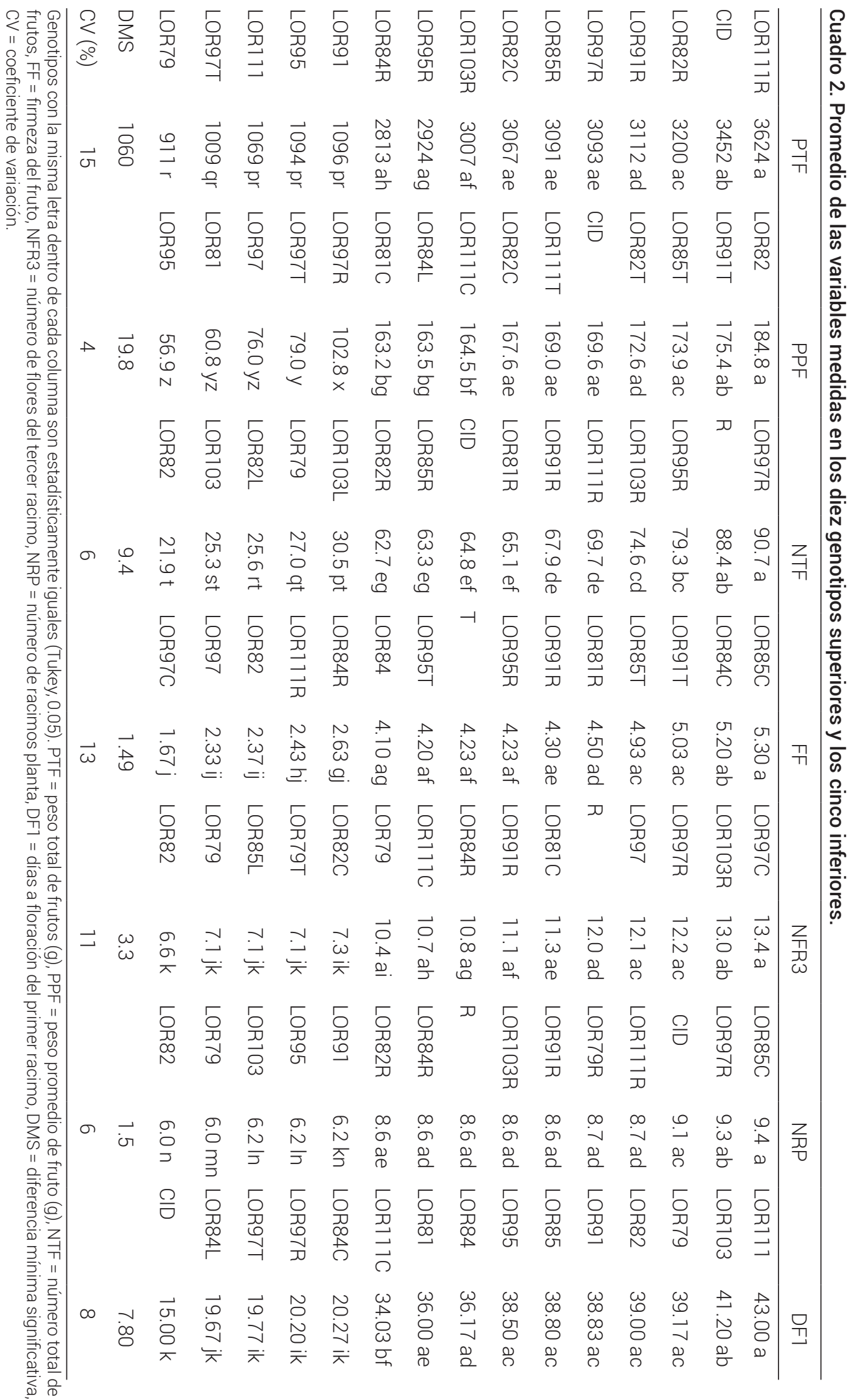


El Cid (169.6 g/fruto). El tamaño grande de fruto de la línea LOR82 per se más el hecho de que sus cruzas con los probadores T y C se ubiquen en el grupo estadísticamente superior, indica que esta línea es una fuente potencial de esta característica. Este desempeño sobresaliente de la línea LOR82 se debe a que proviene de una colecta de frutos de tamaño grande; sin embargo, produce pocos frutos por planta, así como un bajo número de flores por racimo y de racimos por planta, por lo que su rendimiento en general es bajo. Respecto a las cinco cruzas que igualaron al testigo, este resultado se debió probablemente a los efectos de heterosis al combinar germoplasma nativo con germoplasma del tipo "saladette" (Hochholdinger y Hoecker, 2007; Lippman y Zamir, 2006).

La cruza LOR97R superó al híbrido testigo El Cid en número de frutos (91 vs. 65 frutos/planta). Dentro de los mejores materiales genéticos para esta variable están 8 cruzas ( $80 \%$ ) en las que intervino el probador R que ocupó la segunda posición entre los de mayor número de frutos, lo que indica que combina muy bien con el germoplasma nativo para componentes del rendimiento tales como número total de frutos, peso total de frutos, número de flores por racimo y número de racimos por planta.

La firmeza de fruto osciló entre 1.67 y $5.30 \mathrm{~N}$, donde las cruzas predominaron en el grupo superior. Estos valores de firmeza son superiores al promedio del híbrido Caimán (1.59 N) producido en hidroponía por San Martín et al. (2012), quienes apuntaron que la firmeza mínima de los frutos comerciales de tomate es $1.45 \mathrm{~N}$. Por su parte, Hernández-Leal et al. (2013), al estudiar el comportamiento de poblaciones F2 de híbridos comerciales de jitomate tipo "saladette", encontraron valores de firmeza de 1.3 a $2.4 \mathrm{~N}$. Con base en lo anterior, se concluye que algunos de los materiales genéticos de este trabajo tienen una excelente calidad en términos de rendimiento y firmeza, como las cruzas LOR91R y LOR95R que tuvieron rendimientos estadísticamente iguales al testigo y valores de firmeza superiores a $4 \mathrm{~N}$. Para firmeza El Cid tuvo un valor de $3.6 \mathrm{~N}$, por lo que no estuvo entre los 10 mejores genotipos (Cuadro 2) para esta variable, y que todos corresponden a cruzas.

En cuanto al número de flores del tercer racimo, los diez mejores genotipos fueron estadísticamente iguales entre sí, y en ellos predominan las cruzas y únicamente dos líneas per se, con un intervalo de 10 a 13 flores por racimo (Cuadro 2). La cruza LOR97C presentó numéricamente el valor más alto (13 flores por racimo), mientras que la línea de jitomate nativo LOR82 fue el más bajo (6 flores/racimo). El híbrido testigo El Cid tuvo un valor de 9.0 flores por racimo y fue superado por la cruza LOR97C. El número de racimos por planta varió de 6.0 a 9.4, y los valores más altos fueron para las cruzas LOR85C y LOR97R, ambas superio- res al testigo El Cid que formó nueve racimos. Estas dos cruzas fueron estadísticamente iguales a las siete cruzas más sobresalientes.

Con respecto a los días a floración del primer racimo, todas las líneas de jitomate nativo fueron tardías (36 a 43 $\mathrm{d}$ después del trasplante, ddt), sin diferencias estadísticas entre ellas, mientras que los cinco materiales genéticos más precoces fueron las cruzas y el testigo (menos de 34 ddt) (Cuadro 2). Estos resultados son similares a los encontrados por Juárez-López et al. (2012), quienes reportaron la floración del primer racimo en un intervalo de 42 a 46 ddt en líneas de tomate nativo tipo "cherry" provenientes de Guerrero y Puebla; estos autores también mencionaron que los genotipos más precoces a la primera floración se relacionan con los que se cosechan más temprano en el primer racimo, característica deseable en variedades cultivadas. En 49 colectas de jitomate nativo de Oaxaca y crecidas en invernadero, Carrillo-Rodríguez y Chávez-Servia (2010) encontraron que la floración ocurrió de los 17 a los 28 ddt; es decir, fueron más precoces que los materiales aquí evaluados, debido a que se trató de materiales tipo "cherry" y "arriñonados" que se caracterizan por ser en general más precoces.

En este estudio predominaron materiales que resultaron tardíos, de acuerdo con lo indicado por Juárez-López et al. (2012). No obstante, se encontraron cuatro cruzas prometedoras en precocidad (LOR84C, LOR97R, LOR97T y LOR84L), las cuales igualaron estadísticamente al testigo El Cid (15 ddt). Es importante señalar que de estas cuatro cruzas la LOR97R igualó estadísticamente al testigo en rendimiento (PTF), lo que la convierte en germoplasma muy prometedor.

\section{Correlación fenotípica}

El rendimiento total expresado como peso total de fruto (PTF) estuvo significativa y positivamente correlacionado (Cuadro 3) con el peso promedio de fruto $(0.39 * *)$, número total de frutos $(0.61 * *)$, número de flores del racimo 3 $(0.37 * *)$, y número de racimos totales $(0.66 * *)$. La firmeza del fruto no estuvo asociada con el rendimiento, pero sí con días a floración, aunque de manera negativa. Estos resultados indican que el aumento del rendimiento en los materiales evaluados se asoció principalmente con incrementos en NRP, NTF y PPF, y con ligeros decrementos en DF1, variables en las cuales conviene que el mejorador enfoque su atención al efectuar selección genotécnica en este tipo de germoplasma.

\section{Comportamiento per se de líneas y probadores}

Aunque ninguna de las líneas y de los probadores per se 
lograron igualar el rendimiento del híbrido El Cid, con el objeto de interpretar la importancia heterótica de las cruzas entre líneas y probadores es de destacar que hubo líneas como LOR82 y LOR84 para peso promedio de fruto; el probador R para número total de frutos por planta; casi todas las líneas y probadores para número de flores del tercer racimo y firmeza del fruto; y los probadores $C, R$ y $T$ para el número de racimos por planta, que se ubicaron en el mismo grupo estadístico que el testigo El Cid (Cuadro 4). Esta información evidencia el valor genético tanto de las líneas como de los probadores aquí utilizados, ya que nueve de sus combinaciones híbridas igualaron estadísticamente el rendimiento del testigo.

\section{Heterosis}

En las diez cruzas de más alta heterosis con respecto al progenitor medio $(\mathrm{Hm})$ se obtuvieron valores altos y positivos en todas las variables, excepto en días a floración del primer racimo (Cuadro 5). Para peso total de fruto, la Hm media varió de -21.8 a $111.2 \%$, y 37 de las 40 cruzas tuvieron valores positivos lo cual indica que hubo una interacción deseable entre los genes de las líneas y los probadores para esta variable. Las cruzas LOR111R, LOR81C, LOR79C y LOR84C presentaron los valores más altos de Hm, entre 90.3 y $111.2 \%$.

El mayor rendimiento (3624.5 g/planta; Cuadro 2), y la mayor Hm (111.2 \%; Cuadro 5) los presentaron el híbrido LOR111R y cinco híbridos que se ubicaron en el grupo superior del PTF (LOR111R, LOR91R, LOR97R LOR103R y LOR82C), éstos se ubicaron en el grupo superior de heterosis, probablemente debido a una alta divergencia genética entre las fuentes de germoplasma y a una interacción alta y positiva entre los alelos para rendimiento y sus componentes, especialmente con el probador $\mathrm{R}$. Al respecto, Romero et al. (2002) y Birchler et al. (2010) señalaron que la heterosis es un indicador de la divergencia genética, aun- que la ausencia de heterosis no necesariamente es una falta de tal divergencia.

La Hm para las demás variables presentó valores inferiores a la de PTF; i. e., para peso promedio de fruto osciló de -13.3 a $80.7 \%$ y y para número de frutos por planta varió de 12.4 a $58.8 \%$. Las variables PPF y NTF son dos componentes importantes del rendimiento total por planta, que generalmente están correlacionadas negativamente (De Souza et al., 2012; Monamodi et al., 2013). En este contexto destaca que siete cruzas que se ubican en el grupo superior de heterosis para PTF (LOR82C, LOR81C, LOR97C, LOR103C, LOR103R, LOR84C, LOR97R), también se ubicaron en el grupo superior de heterosis para NTF, pero ninguna estuvo en el grupo de alta heterosis para PPF, excepto LOR81C. Después del rendimiento por planta el peso promedio de fruto fue el que presentó la mayor heterosis, lo cual coincide con lo reportado por Singh et al. (2012) quienes encontraron que para esta variable la heterosis fluctuó de -57 a $103 \%$ en 21 cruzas evaluadas.

En número de flores por racimo la heterosis fluctuó entre - 21.1 y $31.3 \%$; los valores más altos fueron los obtenidos en las cruzas donde intervinieron los probadores $\mathrm{C}, \mathrm{R}$ y $\mathrm{T}$. Hannan et al. (2007) encontraron que el valor de heterosis para flores del tercer racimo varió de -25.9 a $37.9 \%$ en cruzas de tomate de origen diverso. Para número de racimos por planta los valores oscilaron de -8.8 a $27.9 \%$, y los valores más altos ocurrieron en las cruzas LOR85C, LOR79R, LOR82R y LOR111R, en las cuales participó como probador la línea $R$. Para días a floración del primer racimo la heterosis varió de -36.1 a $9.8 \%$, donde únicamente los dos primeros valores del Cuadro 5 resultaron positivos, y los restantes 38 valores fueron negativos; esto indica, que en general los híbridos fueron más precoces en floración que sus progenitores, especialmente en comparación con las líneas hembra que fueron las más tardías.

Cuadro 3. Correlaciones fenotípicas de siete variables agronómicas de 55 genotipos de jitomate evaluados en invernadero.

\begin{tabular}{lcccccc}
\hline & PPF & NTF & FF & NFR3 & NRP & DF1 \\
\hline PTF & $0.39 * *$ & $0.61 * *$ & $-0.03 \mathrm{~ns}$ & $0.37 * *$ & $0.66 * *$ & $-0.42 * *$ \\
PPF & & $-0.14 \mathrm{~ns}$ & $0.11 \mathrm{~ns}$ & $-0.17 *$ & $0.11 \mathrm{~ns}$ & $-0.03 \mathrm{~ns}$ \\
NTF & & & $-0.01 \mathrm{~ns}$ & $0.69 * *$ & $0.61 * *$ & $-0.35 * *$ \\
FF & & & $-0.16 *$ & $0.06 \mathrm{~ns}$ & $0.04 \mathrm{~ns}$ \\
NFR3 & & & & $0.49 * *$ & $-0.27 * *$ \\
NRP & & & & & $-0.69 * *$ \\
\hline
\end{tabular}

$* *=$ altamente significativo $(P \leq 0.01), *=$ significativo $(P \leq 0.05), n s=$ no significativo; $P T F=$ peso total de frutos, PPF $=$ peso promedio de frutos, NTF = número total de frutos, FF = firmeza del fruto, NFR3 = número de flores del tercer racimo, NRP = número de racimos por planta, DF1 = días a floración del primer racimo. 
Cuadro 4. Comparación de medias de 10 líneas y 4 probadores per se, así como del híbrido El Cid (testigo).

\begin{tabular}{lccccccc}
\hline Genotipo & PTF & PPF & NTF & FF & NFR3 & NRP & DF1 \\
\hline LOR85 & $1245.0 \mathrm{mr}$ & $131.2 \mathrm{~ms}$ & $33.7 \mathrm{~ns}$ & $3.8 \mathrm{bi}$ & $7.5 \mathrm{hk}$ & $6.4 \mathrm{in}$ & $38.8 \mathrm{ac}$ \\
LOR91 & $1096.1 \mathrm{pr}$ & $131.5 \mathrm{~ms}$ & $34.0 \mathrm{~ns}$ & $4.0 \mathrm{ag}$ & $9.1 \mathrm{ck}$ & $6.2 \mathrm{kn}$ & $38.8 \mathrm{ac}$ \\
LOR95 & $1094.2 \mathrm{pr}$ & $56.9 \mathrm{z}$ & $35.5 \mathrm{mq}$ & $3.9 \mathrm{ah}$ & $8.2 \mathrm{fk}$ & $6.2 \mathrm{ln}$ & $38.5 \mathrm{ac}$ \\
LOR103 & $1136.5 \mathrm{or}$ & $126.0 \mathrm{pv}$ & $25.3 \mathrm{st}$ & $2.7 \mathrm{gj}$ & $7.8 \mathrm{fk}$ & $6.2 \mathrm{ln}$ & $41.2 \mathrm{ab}$ \\
LOR81 & $1116.6 \mathrm{or}$ & $60.8 \mathrm{yz}$ & $35.4 \mathrm{mq}$ & $2.8 \mathrm{ej}$ & $7.9 \mathrm{fk}$ & $6.7 \mathrm{hn}$ & $36.0 \mathrm{ae}$ \\
LOR79 & $911.1 \mathrm{r}$ & $106.3 \mathrm{vx}$ & $27.0 \mathrm{gt}$ & $3.7 \mathrm{ci}$ & $7.1 \mathrm{jk}$ & $6.0 \mathrm{mn}$ & $39.2 \mathrm{ac}$ \\
LOR82 & $2096.7 \mathrm{dp}$ & $184.8 \mathrm{a}$ & $22.0 \mathrm{t}$ & $2.4 \mathrm{ji}$ & $6.6 \mathrm{k}$ & $6.0 \mathrm{n}$ & $39.0 \mathrm{ac}$ \\
LOR111 & $1068.7 \mathrm{gr}$ & $138.8 \mathrm{is}$ & $39.3 \mathrm{kp}$ & $3.6 \mathrm{ci}$ & $7.5 \mathrm{hk}$ & $6.3 \mathrm{jn}$ & $43.0 \mathrm{a}$ \\
LOR84 & $1224.8 \mathrm{mr}$ & $157.9 \mathrm{bi}$ & $33.4 \mathrm{~ns}$ & $4.1 \mathrm{ag}$ & $7.7 \mathrm{gk}$ & $7.0 \mathrm{fn}$ & $36.2 \mathrm{ad}$ \\
LOR97 & $1172.7 \mathrm{nr}$ & $76.0 \mathrm{yz}$ & $55.0 \mathrm{gi}$ & $2.3 \mathrm{ji}$ & $12.1 \mathrm{ac}$ & $7.8 \mathrm{ci}$ & $22.7 \mathrm{hk}$ \\
L & $2197.5 \mathrm{dn}$ & $130.4 \mathrm{~ms}$ & $33.3 \mathrm{~ns}$ & $3.6 \mathrm{ci}$ & $8.1 \mathrm{ek}$ & $7.7 \mathrm{dk}$ & $25.4 \mathrm{gj}$ \\
C & $1391.9 \mathrm{lr}$ & $134.9 \mathrm{ks}$ & $39.9 \mathrm{jo}$ & $4.0 \mathrm{ag}$ & $9.8 \mathrm{bk}$ & $8.3 \mathrm{ag}$ & $26.1 \mathrm{gj}$ \\
R & $2363.1 \mathrm{cl}$ & $127.1 \mathrm{ou}$ & $88.4 \mathrm{ab}$ & $3.4 \mathrm{di}$ & $12.0 \mathrm{ad}$ & $8.6 \mathrm{ad}$ & $27.5 \mathrm{fj}$ \\
T & $1407.4 \mathrm{lr}$ & $104.2 \mathrm{wx}$ & $40.9 \mathrm{jo}$ & $4.2 \mathrm{af}$ & $7.5 \mathrm{hk}$ & $8.1 \mathrm{ah}$ & $23.2 \mathrm{hj}$ \\
CID & $3452.2 \mathrm{ab}$ & $169.6 \mathrm{ae}$ & $64.8 \mathrm{ef}$ & $3.7 \mathrm{ci}$ & $9.9 \mathrm{bk}$ & $9.1 \mathrm{ac}$ & $15.0 \mathrm{k}$ \\
DMS & 1060.4 & 19.8 & 9.4 & 1.5 & 3.3 & 1.5 & 7.8 \\
CV (\%) & 15 & 4 & 6 & 13 & 11 & 6 & 8 \\
\hline
\end{tabular}

Genotipos con la misma letra son estadísticamente iguales (Tukey, 0.05). DMS = diferencia mínima significativa, CV = coeficiente de variación, PTF = peso total de frutos, PPF = peso promedio de fruto $(\mathrm{g}), \mathrm{NTF}=$ número total de frutos, FF = firmeza del fruto, NFR3 = número de flores del tercer racimo, $\mathrm{NRP}=$ número de racimos planta, DF1 = días a floración del primer racimo.

Este resultado se considera bueno para el mejoramiento genético del jitomate, ya que lo que se busca son valores grandes y positivos de heterosis en rendimiento y bajos y negativos en días a floración, con lo cual se producirán cosechas más tempranas de buen rendimiento. Estos resultados coinciden con los de Hannan et al. (2007) quienes al evaluar 45 cruzas y sus 10 progenitores encontraron que las cruzas fueron más precoces, con heterosis negativa para floración que en la mayoría de ellas varió de -31.4 a $4.4 \%$.

De manera general se aprecia que los niveles de heterosis de las 40 cruzas variaron dependiendo de la variable en estudio; así, de las siete variables estudiadas las que presentaron mayor heterosis fueron: rendimiento medido como peso total de fruto (111 \%), PPF (80 \%) y NTF (58\%). Los niveles más bajos de heterosis se observaron en las variables firmeza de fruto con -47.9 \% y en días a floración con $-36.1 \%$.

Estos resultados están en concordancia con los obtenidos por Ahmad et al. (2011) quienes al evaluar la heterosis para rendimiento y sus componentes, encontraron que el número de frutos y rendimiento por planta fueron los que presentaron la máxima heterosis con 84 y $62 \%$, respectivamente. Esta misma tendencia se observó para el caso de la heterosis superior, aunque con valores máximos menores a los de la heterosis media. Esto es ventajoso porque se pueden identificar cruzas superiores en desempeño a los mejores progenitores, que es uno de los objetivos primordiales en el mejoramiento genético del tomate comercial.

Para peso total de fruto las mejores cruzas involucraron a las líneas nativas mexicanas LOR1 11, LOR81, LOR 79, LOR84, LOR 103 y a los probadores $\mathrm{R}$ y C. Los resultados anteriores pueden atribuirse a la alta divergencia genética entre las líneas parentales, así como a su proceso de selección, pues se combinó germoplasma nativo mexicano con germoplasma elite comercial de tipo "saladette" (Birchler et al., 2010). Esto confirma que los materiales genéticos aquí estudiados son adecuados para formar híbridos con alto potencial de rendimiento y con buena firmeza de fruto, o derivar de ellos y de sus cruzas a líneas más avanzadas que al cruzarse tengan una combinación entre ellas aún mejor. 
Cuadro 5. Heterosis con respecto al progenitor medio $\mathrm{Hm}$ y al mejor progenitor $\mathrm{Hs}$ (entre paréntesis) de las diez cruzas de más alta y las cinco de más baja heterosis media para cada variable.

\begin{tabular}{|c|c|c|c|c|c|c|c|c|c|c|c|}
\hline & PTF & & & PPF & & & NTF & & & FF & \\
\hline LOR111R & 111.2 & $(53.4)$ & LOR95T & 80.7 & (39.6) & LOR82C & 58.8 & $(23.1)$ & LOR81R & 43.9 & $(33.1)$ \\
\hline LOR81C & 104.3 & $(84.1)$ & LOR81C & 66.8 & $(21.0)$ & LOR81C & 46.9 & $(38.7)$ & LOR82R & 35.2 & (15.6) \\
\hline LOR79C & 94.4 & $(60.8)$ & LOR81T & 57.1 & $(24.4)$ & LOR79C & 30.5 & (9.4) & LOR85C & 34.9 & $(31.4)$ \\
\hline LOR84C & 90.3 & (78.9) & LOR81L & 54.0 & $(12.9)$ & LOR103C & 30.0 & $(6.2)$ & LOR82L & 30.0 & (8.3) \\
\hline LOR103C & 84.6 & $(67.7)$ & LOR95L & 52.8 & $(9.7)$ & LOR103R & 31.3 & $(-15.6)$ & LOR84C & 27.8 & $(26.9)$ \\
\hline LOR91C & 82.2 & $(62.8)$ & LOR91T & 48.8 & $(33.4)$ & LOR95R & 28.0 & $(-10.3)$ & LOR91T & 22.7 & $(19.2)$ \\
\hline LOR91R & 80.0 & $(31.7)$ & LOR85T & 47.8 & $(32.6)$ & LOR84C & 27.0 & (16.6) & LOR85T & 22.1 & $(16.0)$ \\
\hline LOR82C & 75.8 & $(46.3)$ & LOR95R & 41.1 & $(2.1)$ & LOR97R & 26.5 & (2.6) & LOR91R & 17.1 & (8.8) \\
\hline LOR97R & 75.0 & $(30.9)$ & LOR111T & 39.1 & $(21.8)$ & LOR97C & 16.0 & $(0.0)$ & LOR95R & 16.6 & $(8.7)$ \\
\hline LOR103R & 71.8 & $(27.2)$ & LOR81R & 36.2 & $(0.7)$ & LOR95L & 13.8 & $(10.2)$ & LOR97R & 13.2 & $(-3.7)$ \\
\hline LOR103T & 7.6 & $(-2.8)$ & LOR91R & -1.7 & $(-3.3)$ & LOR91T & -6.7 & $(-14.6)$ & LOR81L & -6.1 & $(-15.5)$ \\
\hline LOR97L & 4.8 & $(-19.7)$ & LOR103L & -6.7 & $(-8.2)$ & LOR84T & -8.6 & $(17.0)$ & LOR85L & -12.4 & $(-14.9)$ \\
\hline LOR82T & -2.7 & $(-18.7)$ & LOR82L & -10.5 & $(-23.6)$ & LOR91C & -9.0 & $(-15.7)$ & LOR111T & -24.0 & $(-30.0)$ \\
\hline LOR82L & -5.0 & $(-7.1)$ & LOR97T & -12.3 & $(-24.2)$ & LOR97L & -10.7 & $(-28.4)$ & LOR91C & -31.3 & $(-31.6)$ \\
\hline \multirow[t]{2}{*}{ LOR97T } & -21.8 & $(-28.3)$ & LOR84R & -13.3 & $(-21.8)$ & LOR111C & -12.4 & $(-13.0)$ & LOR97C & -47.9 & $(-58.7)$ \\
\hline & NFR3 & & & NRP & & & DF1 & & & & \\
\hline LOR103R & 31.3 & (8.3) & LOR85C & 27.9 & $(13.1)$ & LOR97L & 9.8 & (3.9) & & & \\
\hline LOR81C & 27.7 & (14.9) & LOR79R & 19.4 & $(1.6)$ & LOR95T & 5.7 & $(-15.3)$ & & & \\
\hline LOR111C & 22.9 & (8.3) & L082R & 17.1 & $(-0.6)$ & LOR103L & -1.5 & $(-20.4)$ & & & \\
\hline LOR97C & 21.9 & (10.3) & LOR111R & 17.0 & (1.6) & LOR85T & -2.6 & $(-22.2)$ & & & \\
\hline LOR111T & 13.8 & (13.8) & LOR82C & 16.2 & $(0.0)$ & LOR97C & -7.4 & $(-13.4)$ & & & \\
\hline LOR79C & 12.5 & $(-3.4)$ & LOR103R & 16.2 & $(0.0)$ & LOR103T & -8.7 & $(-28.6)$ & & & \\
\hline LOR85T & 11.4 & $(11.1)$ & LOR91R & 16.0 & $(0.0)$ & LOR111T & -11.8 & $(-32.1)$ & & & \\
\hline LOR82T & 10.6 & $(4.0)$ & LOR91L & 15.1 & $(4.3)$ & LOR95R & -12.7 & $(-25.2)$ & & & \\
\hline LOR84R & 9.8 & $(-10.0)$ & LOR81L & 14.8 & $(7.8)$ & LOR81L & -13.4 & $(-26.1)$ & & & \\
\hline LOR79R & 9.2 & $(-13.3)$ & LOR111L & 13.3 & (3.5) & LOR81R & -13.7 & $(23.9)$ & & & \\
\hline LOR82R & -9.0 & $(-29.4)$ & LOR91T & -3.5 & $(-14.8)$ & LOR95L & -23.0 & $(-37.0)$ & & & \\
\hline LOR82C & -11.0 & $(-25.6)$ & LOR97T & -4.8 & $(-6.8)$ & LOR79C & -26.8 & $(-39.1)$ & & & \\
\hline LOR91L & -11.5 & $(-16.2)$ & LOR85T & -5.5 & $(-15.6)$ & LOR85L & -30.2 & $(-42.3)$ & & & \\
\hline LOR95C & -12.3 & $(-19.5)$ & LOR84T & -5.7 & $(-12.3)$ & LOR84C & -34.9 & $(-44.0)$ & & & \\
\hline LOR97L & -21.1 & $(-34.1)$ & LOR81T & -8.8 & $(-16.7)$ & LOR84L & -36.1 & $(-45.6)$ & & & \\
\hline
\end{tabular}

PTF = peso total de frutos, PPF = peso promedio de frutos, NTF = número total de frutos, FF = firmeza del fruto, NFR3 = número de flores del tercer racimo, NRP = número de racimos por planta, DF1 = días a floración del primer racimo. Heterosis media (valores sin paréntesis), heterosis superior (valores entre paréntesis). 


\section{CONCLUSIONES}

Las cruzas entre líneas derivadas de germoplasma nativo "chino criollo" y tipo "saladette" presentaron un alto potencial de rendimiento, ya que las nueve mejores cruzas igualaron el rendimiento del híbrido testigo El Cid cuando las líneas progenitoras se cruzaron con el probador R. Las cruzas fueron superiores al comportamiento per se de las líneas.

Los valores de heterosis media fueron altos y positivos en la mayoría de las variables, con excepción de días a floración que correlacionó negativamente con rendimiento. Los híbridos F1 fueron más precoces que las líneas parentales. Los valores de heterosis variaron según la variable en estudio; la mayor heterosis se obtuvo en peso total de fruto, y la menor se presentó en firmeza de fruto y días a floración.

Para peso total de fruto las mejores cruzas fueron las que involucraron a las líneas nativas mexicanas LOR111, LOR81, LOR79, LOR84 y LOR103, y a los probadores $R$ y C, por lo que estas líneas pueden usarse para el mejoramiento genético de la especie.

\section{BIBLIOGRAFÍA}

Ahmad S., A. K. M. Quamruzzaman and M. R. Islam (2011) Estimate of heterosis in tomato (Solanum lycopersicum L.). Bangladesh Journal of Agricultural Research 36:521-527.

Álvarez H. J. C., H. Cortez-Madrigal e I. García-Ruíz (2009) Exploración y caracterización de poblaciones silvestres de jitomate (Solanaceae) en tres regiones de Michoacán, México. Polibotánica 28:139-159

Birchler J. A., H. Yao, S. Chudalayandi, D. Vaiman and R. A. Veitia (2010) Heterosis. The Plant Cell 22:2105-2112.

Bonilla-Barrientos 0., R. Lobato-Ortiz, J. J. García-Zavala, S. Cruz-Izquierdo, D. Reyes-López, E. Hernández-Leal y A. Hernández-Bautista (2014) Diversidad agronómica y morfológica de tomates arriñonados y tipo pimiento de uso local en Puebla y Oaxaca, México. Revista Fitotecnia Mexicana 37:129-139.

Carrillo-Rodríguez J. y J. L. Chávez-Servia (2010) Caracterización agromorfológica de muestras de tomate de Oaxaca. Revista Fitotecnia Mexicana 33:1-6.

Charlesworth D. and B. Charlesworth (1987) Inbreeding depression and its evolutionary consequences. Annual Review of Ecology and Systematics 18:237-268.

Chávez-Servia J. L., J. C. Carrillo-Rodríguez, A. M. Vera-Guzmán, E. Rodríguez-Guzmán y R. Lobato-Ortiz (2011) Utilización Actual y Potencial del Jitomate Silvestre Mexicano. Ed. Subsistema Nacional de Recursos Fitogenéticos para la Alimentación y la Agricultura (SINAREFI), Secretaria de Agricultura, Ganadería, Desarrollo Rural, Pesca y Alimentación, CIIDIR-Unidad Oaxaca del Instituto Politécnico Nacional e Instituto Tecnológico del Valle de Oaxaca, México. 72 p.

Crisanto-Juárez A. U., A. M. Vera-Guzmán, J. L. Chávez-Servia y J. C. Carrillo-Rodríguez (2010) Calidad de frutos de tomates silvestres (Lycopersicon esculentum var. cerasiforme Dunal) de Oaxaca, México. Revista Fitotecnia Mexicana 33:7-13.

De Souza L. M., P. C. T. Melo, R. R. Luders and A. M. T. Melo (2012) Correlations between yield and fruit quality characteristics of fresh market tomatoes. Horticultura Brasileira 30:627-631.

Escorcia G. N., J. Molina G., F. Castillo G. y J. Mejía C (2010) Rendimiento, heterosis y depresión endogámica de cruzas simples de maíz. Revista Fitotecnia Mexicana 33:271-279.

Estrada-Trejo V., R. Lobato-Ortiz, G. García-de los Santos, G. Carrillo-Castañeda, G. F. Castillo, M. E. Contreras, O. J. Ayala-Garay, M. De la O Olan y M. A. Artola (2014) Diversidad de poblaciones nativas de jitomate para germinación en condiciones salinas. Revista Mexicana de Ciencias Agrícolas 5:1067-1079.

Grandillo S., D. Zamir and S. D. Tanksley (1999) Genetic improvement of processing tomatoes: A 20 years perspective. Euphytica 110:85-97.

Hannan M. M., M. B. AHmed, M. A. Razvy, R. Karim, M. Khatun, A. Haydar, M. Hossain and U. K. Roy (2007) Heterosis and Correlation of yield and yield components in tomato (Lycorpersicon esculentum Mill.). American-Eurasian Journal of Scientific Research 2:146150.

Hernández-Bautista A., R. Lobato-Ortiz, S. Cruz-Izquierdo, J. J. García-Zavala y J. L. Chávez-Servia (2014) Variación fenotípica, heterosis y heredabilidad de una cruza interespecífica de jitomate. Interciencia 39:327-332.

Hernández-Leal E., R. Lobato-Ortiz, J. J. García-Zavala, D. Reyes-López, A. Méndez-López, 0. Bonilla-Barrientos y A. Hernández-Bautista (2013) Comportamiento agronómico de poblaciones $F_{2}$ de híbridos de tomate (Solanum lycopersicum L.). Revista Fitotecnia Mexicana 36:209-215

Hochholdinger F. and N. Hoecker (2007) Towards the molecular basis of heterosis. TRENDS in Plant Science 12:427-432.

Juárez-López P., R. Castro-Brindis, T. Colinas-León, M. Sandoval-Villa, P. Ramírez-Vallejo, D. W. Reed, L. Cisneros-Zevallos y S. King (2012) Evaluación de características de interés agronómico de siete genotipos nativos de jitomate (Lycopersicon esculentum Mill.) cultivados en hidroponía. Revista Chapingo Serie Horticultura 18:207-216

Lippman Z. B. and D. Zamir (2006) Heterosis: revisiting the magic. TRENDS in Genetics 23:60-65.

Lobato-Ortiz R., E. Rodríguez-Guzmán, J. C. Carrillo-Rodríguez, J. L. ChávezServia, P. Sánchez-Peña y A. Aguilar-Meléndez (2012) Exploración Colecta y Conservación de Recursos Genéticos de Jitomate: Avances en la Red de Jitomate. Sistema Nacional de Recursos Fitogenéticos para la Alimentación y la Agricultura (SINAREFI), Secretaría de Agricultura, Ganadería, Desarrollo Rural, Pesca y Alimentación, y Colegio de Postgraduados. Texcoco, México. $54 \mathrm{p}$.

Miller J. C. and S. D. Tanksley (1990) RFLP analysis of phylogenetic relationships and genetic variation in the genus Lycopersicon. Theoretical and Applied Genetics 80:437-448.

Monamodi E. L., D. M. Lungu and G. L. Fite (2013) Analysis of fruit yield and its components in determinate tomato (Lycopersicon lycopersci) using correlation and path coefficient. Botswana Journal of Agriculture and Applied Sciences 9:29-40.

Pacheco-Triste I. A., J. L. Chávez Servia y J. C. Carrillo-Rodríguez (2014) Relación entre variación ecológica-orográfica y variabilidad morfológica de tomate (Solanum lycopersicum L.) en Oaxaca. Revista Mexicana de Agroecosistemas 1:28-39.

Ramanatha R. V. and T. Hodking (2002) Genetic diversity and conservation and utilization of plant genetic resources. Plant Cell, Tissue and Organ Culture 68:1-19.

Reyes L. D., J. Molina G., M. Oropeza R. y E. Moreno P. (2004) Cruzas dialélicas entre líneas autofecundadas de maíz derivadas de la raza Tuxpeño. Revista Fitotecnia Mexicana 27:49-56.

Romero P. J., F. G. Castillo y R. Ortega P. (2002) Cruzas de poblaciones nativas de maíz de la raza Chalqueño: II. Grupos genéticos, divergencia genética y heterosis. Revista Fitotecnia Mexicana 25:107-715.

SAS Institute (2002) User's Guide of SAS (Statical Analysis System). SAS Insitute Inc. Cary, N. C. USA. 550 p.

Sánchez-Peña P., K. Oyama, J. Nuñez-Farfán, J. Fornoni, S. Hernández-Verdugo, J. Márquez-Guzmán and J. A. Garzón-Tiznado (2006) Sources of resistance of whitefly (Bemisia spp.) in wild populations of Solanum lycopersicum var. Cerasiforme (Dunal) Spooner G J, Anderson et R K Jansen, in Northwestern Mexico. Genetic Resources and Crop Evolution 53:711-719.

San Martín H. C., V. M. Ordaz-Chaparro, P. Sánchez-García, M. T. Beryl Colinas y L. Borges-Gómez (2012) Calidad de tomate (Solanum lycopersicum 
L.) producido en hidroponía con diferentes granulometrías de tezontle. Agrociencia 46:243-254.

Singh N. B., S. H. Wani, A. Haribhushan and R. Nongthomban (2012) Heterosis studies for yield and its components in tomato (S. Iycopersicum L.) under valley conditions of Manipur. VEGETOS 25:257-265.
SIAP, Sistema Integral de Información Agroalimentaia y Pesquera (2013) Cierre de la producción agrícola por cultivo "Modalidad riego + temporal". http://www.siap.gob.mx/cierre-de-la-produccionagricola-por-cultivo/ (Octubre 2014).

Steiner A. A. (1984) The universal nutrient solution. In: Proceedings $6^{\text {th }}$ International Congress on Soillens Culture. Wageningen, The Netherlands. pp:633-650. 